\title{
Evaluation of Three Growth Factors with the Most Controversial Expression Pattern in Osteoarthritic and Non-osteoarthritic Cartilage
}

\author{
Abolfazl Bagherifard 1(1), Masoumeh Azizi 2(i), Azade Amini Kadijani 3(D), Ali Mohammad \\ Sharifi ${ }^{4,5}$ (i) , Abolfazl Akbari ${ }^{\text {(iD) }}$, Alireza Mirzaei ${ }^{1, *}$ (D)
}

1 Bone and Joint Reconstruction Research Center, Shafa Orthopedic Hospital, Iran University of Medical Sciences, Tehran, IR Iran; bagherifd@gmail.com (A.B.);

2 Molecular Medicine Department, Biotechnology Research Center, Pasteur Institute of Iran, Tehran, Iran; mazizi528@gmail.com (M.Z.);

3 Basic and Molecular Epidemiology of Gastrointestinal Disorders Research Center, Research Institute for Gastroenterology and Liver Diseases, Shahid Beheshti University of Medical Sciences, Tehran, Iran; amini.azd@ gmail.com (A.A.K.);

4 Department of Pharmacology and Razi Drug Research Center, School of Medicine, Iran University of Medical Sciences, Tehran, Iran; sharifalim@gmail.com (A.M.S.);

5 Tissue Engineering Group, Department of Orthopedic Surgery, Faculty of Medicine, University of Malaya, Kuala Lumpur, Malaysia; sharifalim@gmail.com (A.M.S.);

6 Colorectal Research Center, Iran University of Medical Sciences, Tehran, Iran; akbariia2006@gmail.com (A.A.);

7 Bone and Joint Reconstruction Research Center, Shafa Orthopedic Hospital, Iran University of Medical Sciences, Tehran, IR Iran; mirzaeialireza26@gmail.com (A.M.);

* Correspondence: mirzaeialireza26@gmail.com;

Scopus Author ID 57192904296

Received: 21.02.2021; Revised: 28.03.2021; Accepted: 5.04.2021; Published: 20.04.2021

Abstract: There is no clear consensus regarding the expression pattern of many growth factors in healthy and osteoarthritic cartilage. In this study, the expression pattern of three controversial cartilage growth factors was compared between osteoarthritic $(n=27)$ and non-osteoarthritic cartilage samples $(\mathrm{n}=14)$. The candidate growth factor included Insulin-like growth factor 1 (IGF-1), Fibroblast Growth Factor 2 (FGF-2), and Bone Morphogenetic Protein 2 (BMP-2). The candidate markers' gene and protein expression were analyzed using relative quantification relative to real-time PCR and ELISA, respectively. The mean IGF-I mRNA and protein expression were 11.1, and 2 folds greater in osteoarthritic cartilage, respectively ( $\mathrm{p}<0.001$ for both). The mean FGF-2 mRNA and protein expression were 6.7 and 1.3 folds greater in osteoarthritic cartilage, respectively $(p<0.001$ and $p=0.003)$. The mean BMP-2 mRNA and protein expression were 3.48 and 1.51 folds greater in osteoarthritic cartilage, respectively $(\mathrm{p}=0.001$ and $\mathrm{p}<0.001)$. A significant positive correlation was found between the mRNA and protein expression of all candidate growth factors. In conclusion, the gene and protein expression of IGF-I, FGF-2, and BMP-2 were significantly higher in the osteoarthritic cartilages when compared with non-osteoarthritic, suggesting them as a therapeutic target in OA treatment.

Keywords: cartilage; osteoarthritis; growth factors; insulin-like growth factor 1 (IGF-1); fibroblast growth factor 2 (FGF-2); bone morphogenetic protein 2 (BMP-2).

(C) 2021 by the authors. This article is an open-access article distributed under the terms and conditions of the Creative Commons Attribution (CC BY) license (https://creativecommons.org/licenses/by/4.0/).

\section{Introduction}

A wide variety of chronic disorders can cause musculoskeletal pain from which osteoarthritis (OA) is considered the most common disabling chronic condition of the aged population $[1,2]$. It is a degenerative joint disorder the articular cartilage destruction 
characterizes that. No definitive treatment is known for osteoarthritis, and current non-surgical treatments mainly aim to slow down OA progression and improve symptoms [3, 4]. Osteotomy or total joint replacement remains the last treatment choice in patients in whom the conservative treatment fails to improve OA pain and disability [3, 5, 6]. More understanding of OA pathogenesis provides valuable information on the underlying mechanisms that contribute to disease progression and develops new therapeutic targets for control of the disease [3]. This information could also contain prognostic, diagnostic, and disease monitoring applications [7].

Cartilage homeostasis is controlled by an appropriate balance between chondrocytes' anabolic and catabolic activities [8]. The proper balance of anabolic and catabolic activities is crucial for maintaining cartilage integrity [9, 10]. In degenerative diseases such as osteoarthritis, this balance is compromised so that the extent of catabolic activities predominates over the anabolic activities, eventually presented as cartilage destruction and OA [11]. Identification of the main players of this balance is a critical step to block or reverse OA's progression efficiently.

Growth factors are the main anabolic factors involved in the differentiation, proliferation, and synthetic activity of cartilage, thereby regulating cartilage's physiological homeostasis [12]. The aberrant expression of various growth factors has been shown in the osteoarthritic cartilage [13]. For this reason, growth factors' manipulation has become a rapidly growing field of orthopedics, aiming to maximize cartilage's healing capacity $[14,15]$. While the role of some growth factors such as Bone Morphogenetic Protein 7 (BMP-7) and Transforming Growth Factor $\beta$ (TGF- $\beta$ ) has been almost cleared in the pathogenesis of OA [16-18], the role of other growth factors such as Fibroblast Growth Factor 2 (FGF-2), Insulinlike growth factor 1 (IGF-1), Bone Morphogenetic Protein 2 (BMP-2) remains controversial [19-23].

In this study, we aimed to compare the expression pattern of IGF-I, FGF-2, and BMP2 between the human osteoarthritic and non-osteoarthritic cartilage samples, to find how the expression of these factors change in osteoarthritic condition.

\section{Materials and Methods}

The review board approved this research of our university and patients provided written informed consent before inclusion in the study.

Osteoarthritic cartilages were taken from knee OA patients who underwent total knee arthroplasty for osteoarthritis grade 4 according to Kellgren and Lawrence classification [24]. OA patients with other joint disorders such as rheumatoid arthritis were excluded from the study. Non-osteoarthritic cartilages were obtained from patients who survived an acute traumatic chondral injury of the knee, which was not fixable, and removal of chondral fragments as indicated. A knee radiograph was obtained to exclude the patients with a radiographic sign of OA. Non-osteoarthritic patients who had a positive history of joint disorders were excluded from the study, as well. Immediately after the excision, the tissue samples were placed into QIAGEN's Allprotect ${ }^{\circledR}$ Tissue Reagent (QIAGEN, Valencia, CA, USA), as the mRNA and protein stabilization solution.

For the gene expression analysis, first, the samples were disrupted and homogenized using the TissueLyser for RNA purification (RNeasy Mini Kit, QIAGEN, Valencia, CA, USA) as described in the manufacturer protocol. Then, the homogenized samples were subjected to RNA extraction process using QIAzol Lysis Reagent (QIAGEN, Valencia, CA, USA). After measuring the concentration of the RNA by spectrophotometer (IMPLEN, Germany) and 
assessment of RNA quality through determining the ratio of absorbance in 260 and $280,1 \mu \mathrm{g}$ of RNA was utilized as a template for reverse transcription into complementary DNA (cDNA) using Revert Aid First Strand cDNA Synthesis Kit (Thermo Scientific, USA). Two microliters of cDNA product were used for the relative quantification Real-time PCR using a set of designed primers (Table 1) at the following condition: initial denaturation at $\left(95^{\circ} \mathrm{C} / 10 \mathrm{~min}\right)$, and 40 cycles of the following steps: denaturation $\left(95{ }^{\circ} \mathrm{C} / 30\right.$ seconds), annealing $\left(59{ }^{\circ} \mathrm{C} / 40\right.$ seconds) and extension $\left(72{ }^{\circ} \mathrm{C} / 30\right.$ seconds). A SYBR ${ }^{\circledR}$ Premix Ex Taq ${ }^{\mathrm{TM}}$ II (Takara, Japan) on StepOnePlus ${ }^{\mathrm{TM}}$ Real-Time PCR System (Applied Biosystems, USA) was used for real-time PCR reactions. Glyceraldehyde 3-phosphate dehydrogenase (GAPDH) was used as the internal reference, and its primer was purchased as predesigned (QT01658692, QIAGEN, Valencia, CA, USA). PCR assays were performed in triplicate, and positive and negative controls were employed in every run. The specificity of reactions was verified by melting curve analysis. Finally, the gene expression data were analyzed using the comparative $\mathrm{Ct}$ method. In this respect, $2^{-\Delta C t}$ was computed for each sample, in which $\Delta \mathrm{Ct}$ is: (CT gene of interest $-\mathrm{CT}$ internal control) [25].

Table 1. Primer pairs used for gene expression analysis.

\begin{tabular}{l|l|c} 
Gene & Primer sequence & Product size \\
\hline FGF2 & $\begin{array}{l}\text { Forward: AGAGCGACCCTCACATCAAG } \\
\text { Reverse: CCGTAACACATTTAGAAGCCAG }\end{array}$ & 132 base pair \\
\hline BMP2 & $\begin{array}{l}\text { Forward: CTGCGGTCTCCTAAAGGTCG } \\
\text { Reverse: CAACTCGAACTCGCTCAGGA }\end{array}$ & 188 base pair \\
\hline IGF-I & $\begin{array}{l}\text { Forward: CTGGTGGATGCTCTTCAGTTC } \\
\text { Reverse: GCCTCCTTAGATCACAGCTCC }\end{array}$ & 142 base pair
\end{tabular}

For the protein expression analysis, cartilage tissues were disrupted and homogenized using the TissueLyser for total protein purification (Qproteome Mammalian Protein Prep Kit, QIAGEN, Valencia, CA, USA) as described in the manufacturer protocol. Then, the total protein was extracted using the RIPA buffer. The extracted proteins were adjusted by Bradford assay to measure protein concentration in the solution and address the inter-sample heterogeneity. Subsequently, manufactured ELISA (enzyme-linked immunosorbent assay) kits were used for the evaluation of the protein expression level of IGF-I (Human IGF-I Quantikine ELISA Kit, DG100, R \& D Systems, Wiesbaden-Nordenstadt, Germany), FGF-2 (Human FGF-2 Quantikine ELISA Kit, DFB50, R \& D Systems, Wiesbaden-Nordenstadt, Germany), and BMP-2 (Human BMP-2 Quantikine ELISA Kit, DBP200, R \& D Systems, WiesbadenNordenstadt, Germany).

SPSS for Windows (version 16) was implemented for statistical evaluations. The descriptive statistics were provided as mean \pm standard deviation or number and percentage. The mean expression of the genes and proteins in osteoarthritic cartilages was compared with the mean expression of genes and proteins in non-osteoarthritic cartilages using an independent t-test or its nonparametric counterpart (Mann-Whitney U test). A p-value of fewer than 0.05 was considered significant.

\section{Results and Discussion}

A total of 27 osteoarthritics and 14 non-osteoarthritic knee cartilage samples were assessed in this study. The patients' mean age was $67.5 \pm 5.8$ years in the osteoarthritic group and $65.2 \pm 8$ years in nonosteoarthritic group. This difference was not statistically significant $(\mathrm{p}=0.22)$. No significant difference was found between the sex distribution and body mass 
index (BMI) of the two study groups. The mean disease duration was $9.2 \pm 5.4$ years. The demographic and clinical characteristics of the patients are demonstrated in Table 2.

Table 2. Clinical and demographic characteristics of patients with knee osteoarthritis.

\begin{tabular}{|c|c|c|c|}
\hline Variable & $\begin{array}{l}\text { Osteoarthritis } \\
\text { patients } \\
(\mathbf{n}=27)\end{array}$ & $\begin{array}{l}\text { Non-osteoarthritic } \\
\text { patients } \\
(n=14)\end{array}$ & P-value \\
\hline Age (year) & $67.5 \pm 5.8$ & $65.2 \pm 8$ & 0.22 \\
\hline $\begin{array}{cl}\text { Gender } & \\
\bullet & \text { Male } \\
\bullet & \text { Female }\end{array}$ & $\begin{array}{l}6(22.2) \\
21(77.8)\end{array}$ & $\begin{array}{l}5(35.7) \\
9(64.3)\end{array}$ & 0.39 \\
\hline $\begin{aligned} \text { Family history } \\
\bullet \quad \text { Positive } \\
\bullet \quad \text { Negative }\end{aligned}$ & $\begin{array}{l}20(74.1) \\
7(25.9)\end{array}$ & $\begin{array}{l}3(21.4) \\
11(75.6)\end{array}$ & $<0.001$ \\
\hline Body mass index $\left(\mathrm{kg} / \mathrm{m}^{2}\right)$ & $24.3 \pm 2.6$ & $24.9 \pm 2.7$ & 0.56 \\
\hline Disease duration & $9.2 \pm 5.4$ & - & \\
\hline $\begin{array}{cc}\text { *Associated disease } \\
\bullet \quad \text { Positive } \\
\bullet \quad \text { Negative }\end{array}$ & $\begin{array}{l}22(81.5) \\
5(18.5)\end{array}$ & $\begin{array}{l}10(71.4) \\
4(28.6)\end{array}$ & 0.34 \\
\hline
\end{tabular}

*Diabetes mellitus, hypertension, or cardiovascular diseases.

The data are shown as mean \pm SD of number $(\%)$

The mean IGF-I mRNA expression was $0.078 \pm 0.057$ in the osteoarthritic and $0.007 \pm 0.002$ in the non-osteoarthritic samples. Accordingly, the mean IGF-I mRNA expression was 11.1 folds greater in osteoarthritic cartilage. This difference was statistically significant ( $\mathrm{p}<0.001$ ). The mean IGF-I protein level was $638.3 \pm 215.6 \mathrm{pg} / \mathrm{ml}$ in the osteoarthritic and $317.4 \pm 132 \mathrm{pg} / \mathrm{ml}$ in the non-osteoarthritic group. Accordingly, the IGF-I protein expression level was two folds greater in osteoarthritic cartilage. This difference was statistically significant, as well $(\mathrm{p}<0.001)$.

The mean FGF-2 mRNA expression was $0.006 \pm 0.004$ in the osteoarthritic and $0.0009 \pm 0.001$ in the non-osteoarthritic samples. Accordingly, the mean FGF-2 mRNA expression was 6.7 folds greater in osteoarthritic cartilage. This difference was statistically significant ( $\mathrm{p}<0.001)$. The mean FGF-2 protein level was $109.3 \pm 39.7 \mathrm{pg} / \mathrm{ml}$ in the osteoarthritic and $82.7 \pm 13.5$ in the non-osteoarthritic group. Accordingly, the FGF-2 protein expression level was 1.3 folds greater in osteoarthritic cartilage. This difference was statistically significant $(\mathrm{p}=0.003)$.

The mean BMP-2 mRNA expression was $0.16 \pm 0.09$ in osteoarthritic and $0.046 \pm 0.04$ in non-osteoarthritic samples. Accordingly, the mean BMP-2 mRNA expression was 3.48 folds greater in osteoarthritic cartilage. This difference was statistically significant $(p=0.001)$. The mean BMP-2 protein level was $70.3 \pm 15 \mathrm{pg} / \mathrm{ml}$ in the osteoarthritic and $46.4 \pm 15.4$ in the nonosteoarthritic group. Accordingly, the BMP-2 protein expression level was 1.51 folds greater in osteoarthritic cartilage. This difference was statistically significant $(p<0.001)$. The expression pattern of growth factors at both mRNA and protein levels has been demonstrated in Figure 1.

The IGF-I mRNA expression significantly correlated with the IGF-I protein expression $(r=0.602, p<0.001)$. A significant correlation was found between the FGF-2 mRNA expression and its protein expression $(\mathrm{r}=0.643, \mathrm{p}<0.001)$. Also, a significant correlation was found between the BMP-2 mRNA and protein expression level $(r=0.669, \mathrm{p}<0.001)$. 

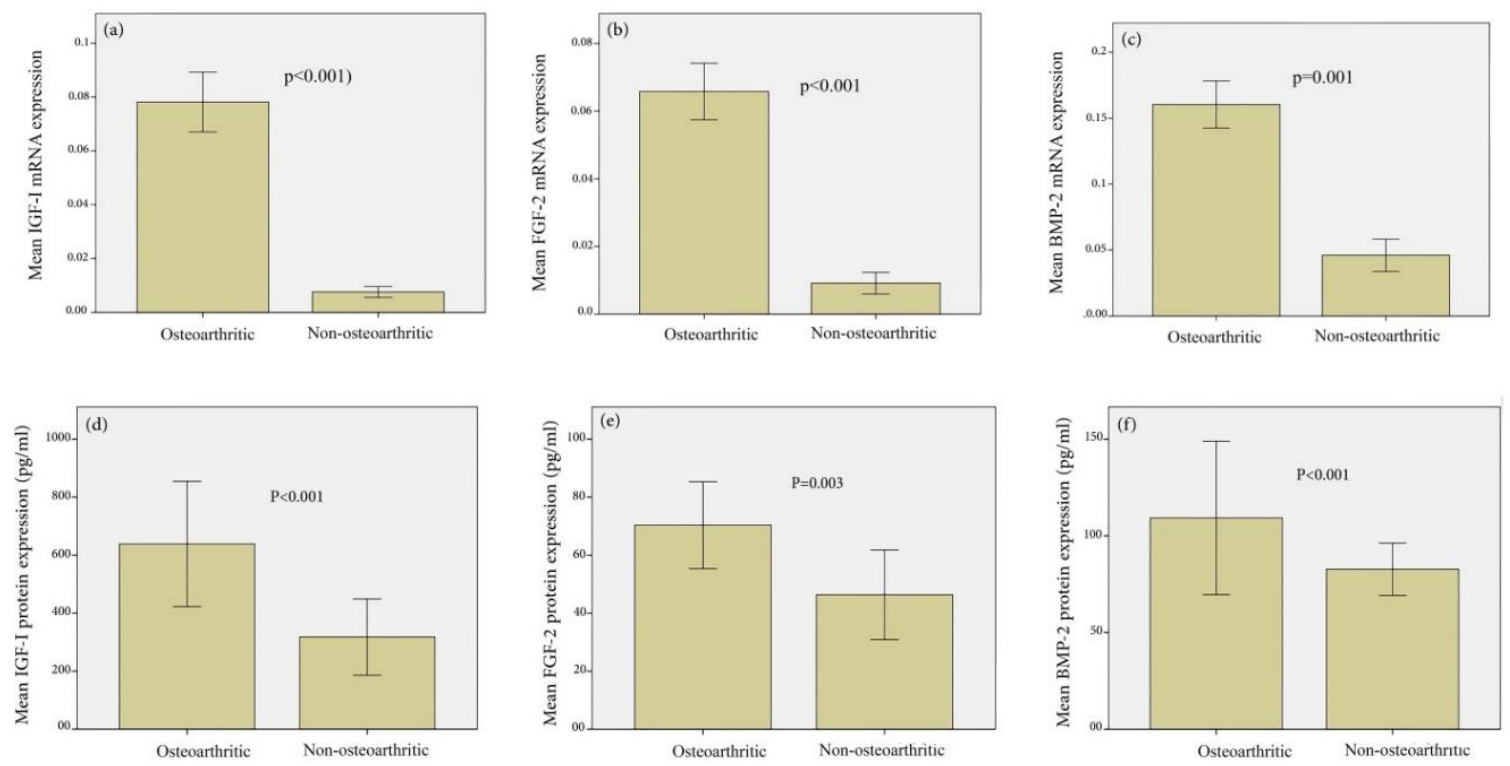

Figure 1. Comparison of growth factors' expression pattern between osteoarthritic and non-osteoarthritic cartilaginous samples: (a) IGF-1 mRNA expression in osteoarthritic and non-osteoarthritic samples; (b) FGF-2 mRNA expression in osteoarthritic and non-osteoarthritic samples; (c) BMP-2 mRNA expression in osteoarthritic and non-osteoarthritic samples; (d) IGF-I protein expression in osteoarthritic and non-osteoarthritic samples; (e) FGF-2 protein expression in osteoarthritic and non-osteoarthritic samples; (f) BMP-2 protein expression in osteoarthritic and non-osteoarthritic samples (data are shown as mean \pm standard deviation).

Based on this study's results, the expression pattern of all evaluated growth factors, including IGF-I, FGF-2, and BMP-2, was significantly more in the osteoarthritic cartilage at both protein and mRNA levels. Moreover, a significant correlation was found between the mRNA and protein expression of the candidate growth factors.

Cartilaginous growth factor expression has been studied in other investigations, as well. However, as obtaining a cartilage sample, particularly from non-osteoarthritic individuals, is difficult, the majority of earlier studies have been performed on cultured chondrocytes or animal models.

Wei et al. aimed to investigate whether the expression of IGF-1 is associated with loss of chondrocyte and extracellular matrix breakdown in the guinea pig model. Based on their results, histological loss of chondrocytes and cartilage matrix was associated with decreased IGF-1 distribution. Decreased level of IGF-1 was also more prominent in the 12-month old compared with 6-month old pigs. Further, these observations were more significant in the medial tibial than the lateral plateau. According to these results, they concluded that the IGF-1 might be applicable for OA therapy [26]. By contrast, in Schneiderman et al., IGF-I level was considerably higher in human osteoarthritic cartilage than normal human cartilage [27]. Furthermore, osteoarthritic chondrocytes are not responsive to IGF-1 owing to the inhibition of IGF-1 ligand-receptor interactions dictated by IGF binding proteins that are highly expressed in osteoarthritic chondrocytes [28]. The present research results also revealed increased IGF-I expression in osteoarthritic cartilage, suggesting a detrimental role for IGF-I in OA pathogenesis.

Studies investigating the FGF-2 role in cartilage have been conflicting. There is not a consensus on whether FGF-2 is a good or bad player in the joint [29]. FGF-2 potently antagonizes BMP-7 and IGF-1 mediated proteoglycan production in human cartilage [30]. It also induces the expression of matrix metalloprotease-13 as the most potent collagen-type II degrading enzyme [31]. By contrast, the study of Chia et al. revealed an accelerated OA 
development in mice lacking FGF2 (FGF2 null mice) [32]. The survey of Yan et al. attributed this controversy to the balance between the two major FGF receptors, FGFR1 and FGFR3. While the catabolic effects of FGF2 are mediated primarily through FGFR1, the anabolic effects of FGF-2 are exerted through FGFR3 [33]. These results suggest that FGF receptors could be more important in OA's pathophysiology than the FGF-2 itself. The current study results revealed a higher FGF-2 gene expression in osteoarthritic cartilage compared with nonosteoarthritic tissue. These results reveal the pathological significance for FGF2 as a major target for drug development and therapeutics in OA, as earlier discussed by Coffin et al. [34].

BMP-2 is demonstrated to have an adverse effect on ECM biosynthesis, and its expression is up-regulated in osteoarthritic chondrocytes $[35,36]$. BMP-2 concentrations in serum and synovial fluid have also revealed a close association with the radiographic and symptomatic severity of knee OA [7, 37]. Nevertheless, in the recent study of Hicks et al., sustained delivery of BMP2 induced the differentiation of muscle-derived stem cells to a chondrocyte lineage for in vivo cartilage regeneration and healing in the osteoarthritis model [38]. In this dilemma, the present study revealed increased BPM-2 expression in osteoarthritic cartilage compared to non-osteoarthritic cartilage.

Shi et al. delivered IGF-I, FGF-2, and/or TGF- $\beta 1$ to adult bovine articular chondrocytes in primary culture and evaluated the resulting alterations in IGF-I, FGF-2, and TGF- $\beta 1$ gene and protein expression. Accordingly, FGF-2 increased FGF-2 mRNA expression to a maximum of 2.7 -fold at $12 \mathrm{~h}$. IGF-I revealed a little effect on IGF-I expression. TGF- $\beta 1$ increased its own mRNA expression $<1$.7-fold from $2 \mathrm{~h}$ through 1 day. FGF-2, IGF-I, and TGF- $\beta 1$ also synergistically regulated each other's gene expression [39]. These results suggest that interaction between growth factors substantially modulate their regulatory functions and should also be considered when trying to use them as disease-modifying agents.

This study was not without limitations. A smaller number of samples in the nonosteoarthritic cartilage group could be regarded as the main limitation of this study, which was dictated by the inability to obtain cartilage samples from healthy individuals. This limitation might have adversely affected the power of statistical analysis. Also, non-osteoarthritic samples were obtained from patients with a traumatic accident. Trauma-induced effects on cartilage growth factors were not considered in this survey, which could be regarded as the other limitation of the study. Therefore, complementary studies are required to fully explore the expression pattern of growth factors in the context of OA.

\section{Conclusions}

The gene expression of IGF-I, FGF-2, and BMP-2 was higher in the osteoarthritic cartilages when compared with non-osteoarthritic cartilages. These higher gene expressions were also reflected in the expression of the corresponding proteins. Therefore, these growth factors could be suggested as a therapeutic target in OA treatment. Even so, further large-scale standardized studies are needed to shed more light on this implication, particularly in elucidating the synergistic and antagonistic interactions between growth factors.

\section{Funding}

This research was funded by the Iran University of Medical Sciences Under the code of 30148. 


\section{Acknowledgments}

This research has no acknowledgment.

\section{Conflicts of Interest}

The authors declare no conflict of interest.

\section{References}

1. Kloppenburg, M.; Berenbaum, F. Osteoarthritis year in review 2019: epidemiology and therapy. Osteoarthritis Cartilage 2020, 28, 242-248, https://doi.org/10.1016/j.joca.2020.01.002.

2. Abramoff, B.; Caldera, F.E. Osteoarthritis: pathology, diagnosis, and treatment options. Med Clin North Am 2020, 104, 293-311, https://doi.org/10.1016/j.mcna.2019.10.007.

3. Ghouri, A.; Conaghan, P.G. Prospects for therapies in osteoarthritis. Calcif Tissue Int 2020, 1-12, https://doi.org/10.1007/s00223-020-00672-9 .

4. Hawker, G.A. Osteoarthritis is a serious disease. Clin Exp Rheumatol 2019, 37, 3-6.

5. Bagherifard, A.; Jabalameli, M.; Mirzaei, A.; Khodabandeh, A.; Abedi, M.; Yahyazadeh, H. Retaining the medial collateral ligament in high tibial medial open-wedge osteotomy mostly results in post-operative intraarticular gap reduction. Knee Surg Sports Traumatol Arthrosc 2019, 1-6, https://doi.org/10.1007/s00167019-05473-8

6. Gao, J.; Xing, D.; Dong, S.; Lin, J. The primary total knee arthroplasty: a global analysis. J Orthop Surg Res 2020, 15, 1-12, https://doi.org/10.1186/s13018-020-01707-5 .

7. Liu, Y.; Hou, R.; Yin, R.; Yin, W. Correlation of bone morphogenetic protein-2 levels in serum and synovial fluid with disease severity of knee osteoarthritis. Med Sci Monit 2015, 21, https://doi.org/10.12659/msm.892160.

8. Roseti, L.; Desando, G.; Cavallo, C.; Petretta, M.; Grigolo, B. Articular cartilage regeneration in osteoarthritis. Cells 2019, 8, https://dx.doi.org/10.3390\%2Fcells8111305.

9. Pritzker, K.P.H.; Gahunia, H.K. Articular Cartilage: Homeostasis, Aging and Degeneration. In: Articular Cartilage of the Knee: Health, Disease and Therapy. Gahunia, H.K.; Gross, A.E.; Pritzker, K.P.H.; Babyn, P.S.; Murnaghan, L. Eds. Springer New York: New York, NY, 2020; pp. 99-122, https://doi.org/10.1007/978-1-4939-7587-7_3.

10. Smith, D.W.; Gardiner, B.S.; Zhang, L.; Grodzinsky, A.J. Cartilage tissue homeostasis. In: Articular Cartilage Dynamics. Springer, Singapore. 2019; pp. 65-243, https://doi.org/10.1007/978-981-13-1474-2.

11. Kolupaeva, V.; Katsara, O.; Attur, M. Translational control maintains cartilage homeostasis and regulates osteoarthritis progression. Osteoarthritis Cartilage 2019, 27, https://doi.org/10.1016/j.joca.2019.02.284.

12. Chen, L.; Liu, J.; Guan, M.; Zhou, T.; Duan, X.; Xiang, Z. Growth Factor and Its Polymer Scaffold-Based Delivery System for Cartilage Tissue Engineering. Int $J$ Nanomedicine 2020, 15, https://dx.doi.org/10.2147\%2FIJN.S249829.

13. Tu, M.; Yao, Y.; Qiao, F.H.; Wang, L. The pathogenic role of connective tissue growth factor in osteoarthritis. Biosci Rep 2019, 39, https://dx.doi.org/10.1042\%2FBSR20191374.

14. Zhang, W.; Robertson, W.B.; Zhao, J.; Chen, W.; Xu, J. Emerging trend in the pharmacotherapy of osteoarthritis. Front Endocrinol 2019, 10, https://doi.org/10.3389/fendo.2019.00431.

15. Alcaraz, M.J.; Guillén, M.I.; Ferrándiz, M.L. Emerging therapeutic agents in osteoarthritis. Biochem Pharmacol 2019, 165, 4-16, https://doi.org/10.1016/j.bcp.2019.02.034.

16. Zhang, W.; Robertson, W.B.; Zhao, J.; Chen, W.; Xu, J. Emerging trend in the pharmacotherapy of osteoarthritis. Front Endocrinol 2019, 10, https://doi.org/10.3389/fendo.2019.00431.

17. Hesari, R.; Keshvarinia, M.; Kabiri, M.; Rad, I.; Parivar, K.; Hoseinpoor, H.; Tavakoli, R.; Soleimani, M.; Kouhkan, F.; Zamanluee, S. Comparative impact of platelet rich plasma and transforming growth factor- $\beta$ on chondrogenic differentiation of human adipose derived stem cells. Bioimpacts: BI 2020, 10.

18. Lu, W.; He, Z.; Shi, J.; Wang, Z.; Wu, W.; Liu, J.; Kang, H.; Li, F.; Liang, S. AMD3100 Attenuates PostTraumatic Osteoarthritis by Maintaining Transforming Growth Factor- $\beta 1$-Induced Expression of Tissue Inhibitor of Metalloproteinase-3 via the Phosphatidylinositol 3-Kinase/Akt Pathway. Front Pharmacol 2020, 10, https://doi.org/10.3389/fphar.2019.01554.

19. Chen, T.-M.; Chen, Y.-H.; Sun, H.S.; Tsai, S.-J. Fibroblast growth factors: Potential novel targets for regenerative therapy of osteoarthritis. Chin J Physiol 2019, 62, https://doi.org/10.4103/cjp.cjp_11_19.

20. Wang, J.; Liu, S.; Li, J.; Yi, Z. The role of the fibroblast growth factor family in bone-related diseases. Chem Biol Drug Des 2019, 94, 1740-1749. https://doi.org/10.1111/cbdd.13588.

21. Hartley, A.; Sanderson, E.; Paternoster, L.; Granell, R.; Tobias, J.; Gregson, C. Mendelian randomization identifies a causal role for serum insulin-like growth factor-1 in hip osteoarthritis. Osteoarthritis Cartilage 2020, 28, https://doi.org/10.1016/j.joca.2020.02.109. 
22. Boushell, M.K.; Mosher, C.Z.; Suri, G.K.; Doty, S.B.; Strauss, E.J.; Hunziker, R.B.; Lu, H.H. Polymeric mesh and insulin-like growth factor 1 delivery enhance cell homing and graft-cartilage integration. Ann $N$ Y Acad Sci 2019, 1442, 138-152, https://doi.org/10.1111/nyas.14054.

23. Chien, S.-Y.; Tsai, C.-H.; Liu, S.-C.; Huang, C.-C.; Lin, T.-H.; Yang, Y.-Z.; Tang, C.-H. Noggin Inhibits IL-1 $\beta$ and BMP-2 Expression, and Attenuates Cartilage Degeneration and Subchondral Bone Destruction in Experimental Osteoarthritis. Cells 2020, 9, https://doi.org/10.3390/cells9040927.

24. Kellgren, J.; Lawrence, J. Radiological assessment of osteo-arthrosis. Ann Rheum Dis 1957, 16, https://doi.org/10.1136/ard.16.4.494.

25. Schmittgen, T.D.; Livak, K.J. Analyzing real-time PCR data by the comparative CT method. Nat Protoc 2008, 3, https://doi.org/10.1038/nprot.2008.73.

26. Wei, F.-Y.; Lee, J.; Wei, L.; Qu, F.; Zhang, J.-Z. Correlation of insulin-like growth factor 1 and osteoarthritic cartilage degradation: a spontaneous osteoarthritis in guinea-pig. E ur Rev Med Pharmacol Sci 2017, 21.

27. Schneiderman, R.; Rosenberg, N.; Hiss, J.; Lee, P.; Liu, F.; Hintz, R.; Maroudas, A. Concentration and size distribution of insulin-like growth factor-I in human normal and osteoarthritic synovial fluid and cartilage. Arch Biochem Biophys 1995, 324, 173-188, https://doi.org/10.1006/abbi.1995.9913.

28. Doré, S.; Pelletier, J.P.; Dibattista, J.A.; Tardif, G.; Brazeau, P.; Martel-Pelletier, J. Human osteoarthritic chondrocytes possess an increased number of insulin-like growth factor 1 binding sites but are unresponsive to its stimulation. Arthritis Rheum 1994, 37, 253-263, https://doi.org/10.1002/art.1780370215.

29. Vincent, T.L. Fibroblast growth factor 2: good or bad guy in the joint? Arthritis Res Ther 2011, 13, https://dx.doi.org/10.1186\%2Far3447.

30. Loeser, R.F.; Chubinskaya, S.; Pacione, C.; Im, H.J. Basic fibroblast growth factor inhibits the anabolic activity of insulin-like growth factor 1 and osteogenic protein 1 in adult human articular chondrocytes. Arthritis Rheum 2005, 52, 3910-3917, https://doi.org/10.1002/art.21472.

31. Wang, X.; Manner, P.A.; Horner, A.; Shum, L.; Tuan, R.S.; Nuckolls, G.H. Regulation of MMP-13 expression by RUNX2 and FGF2 in osteoarthritic cartilage. Osteoarthritis Cartilage 2004, 12, 963-973, https://doi.org/10.1016/j.joca.2004.08.008.

32. Chia, S.L.; Sawaji, Y.; Burleigh, A.; McLean, C.; Inglis, J.; Saklatvala, J.; Vincent, T. Fibroblast growth factor 2 is an intrinsic chondroprotective agent that suppresses ADAMTS-5 and delays cartilage degradation in murine osteoarthritis. Arthritis Rheum 2009, 60, 2019-2027, https://doi.org/10.1002/art.24654.

33. Yan, D.; Chen, D.; Cool, S.M.; Van Wijnen, A.J.; Mikecz, K.; Murphy, G.; Im, H.-J. Fibroblast growth factor receptor 1 is principally responsible for fibroblast growth factor 2-induced catabolic activities in human articular chondrocytes. Arthritis Res Ther 2011, 13, https://doi.org/10.1186/ar3441.

34. Coffin, J.D.; Homer-Bouthiette, C.; Hurley, M.M. Fibroblast growth factor 2 and its receptors in bone biology and disease. J EndocrSoc 2018, 2, 657-671, https://dx.doi.org/10.1210\%2Fjs.2018-00105.

35. Fukui, N.; Zhu, Y.; Maloney, W.J.; Clohisy, J.; Sandell, L.J. Stimulation of BMP-2 expression by proinflammatory cytokines IL-1 and TNF- $\alpha$ in normal and osteoarthritic chondrocytes. J Bone Joint Surg 2003, 85, 59-66, https://doi.org/10.2106/00004623-200300003-00011.

36. Majumdar, M.K.; Chockalingam, P.S.; Bhat, R.A.; Sheldon, R.; Keohan, C.; Blanchet, T.; Glasson, S.; Morris, E.A. Immortalized mouse articular cartilage cell lines retain chondrocyte phenotype and respond to both anabolic factor BMP-2 and pro-inflammatory factor IL-1. J Cell Physiol 2008, 215, 68-76, https://doi.org/10.1002/jcp.21282.

37. Valdes, A.M.; Spector, T.D. Genetic epidemiology of hip and knee osteoarthritis. Nat Rev Rheumatol 2011, 7, https://doi.org/10.1038/nrrheum.2010.191.

38. Hicks, J.J.; Rocha, J.L.; Li, H.; Huard, J.; Wang, Y.; Hogan, M.V. Sustained Release of Bone Morphogenetic Protein 2 via Coacervate improves Muscle Derived Stem Cell Mediated Cartilage Regeneration in MIAinduced Osteoarthritis. Orthop J Sports Med 2016, 4, https://doi.org/10.1177\%2F2325967116S00152.

39. Shi, S.; Mercer, S.; Eckert, G.J.; Trippel, S.B. Growth factor regulation of growth factors in articular chondrocytes. J BiolChem 2009, 284, 6697-6704, https://doi.org/10.1074/jbc.m807859200. 